\title{
Ovarian Sex Cord-Stromal Tumors: An Immunohistochemical Study Including a Comparison of Calretinin and Inhibin
}

Michael T. Deavers, M.D., Anais Malpica, M.D., Jinsong Liu, M.D., Ph.D., Russell Broaddus, M.D., Ph.D., Elvio G. Silva, M.D.

Department of Pathology, The University of Texas M. D. Anderson Cancer Center, Houston, Texas

Because ovarian sex cord-stromal tumors (SCST) are morphologically heterogeneous neoplasms that are relatively infrequently encountered, their diagnosis can be difficult. Immunohistochemical staining may be useful for establishing the diagnosis in problematic cases. We studied 53 ovarian SCSTs to characterize their immunohistochemical staining pattern: 17 adult granulosa cell tumors (AGCTs), 4 juvenile granulosa cell tumors (JGCTs), 3 sex cord tumors with annular tubules (SCTATs), 9 SertoliLeydig cell tumors (SLCTs), 10 fibromas, 5 fibrothecomas (FTs), and 5 thecomas. In 8 of the 53 cases, the tissue studied was from a metastatic site. The immunopanel included calretinin, inhibin, WT1, cytokeratin cocktail, epithelial membrane antigen (EMA), and cytokeratin 5/6 (CK5/6). The fibromas and FTs were also tested with CD10. The extent of staining was assessed in a semiquantitative fashion and ranked on a scale of 0 through $4+$. All of the tumors, except for 1 metastatic SLCT, were positive for calretinin. Forty-five of the cases $(85 \%)$ stained for inhibin; 1 metastatic AGCT, 3 fibromas, and 4 FTs were negative. WT1 was present in 39 tumors (74\%), with expression most prominent in the SLCTs. The cytokeratin cocktail stained 23 of the 53 tumors (43\%), whereas just 1 tumor was positive for EMA $(1+$ in a JGCT). All tumors were negative for CK5/6, and the 15 fibromas and FTs were negative for CD10. We conclude that because cytokeratin is frequently expressed by SCSTs, in particular by granulosa cell tumors, SLCTs, and SCTATs, the inclusion of EMA in a panel may help to exclude

\footnotetext{
Copyright (C) 2003 by The United States and Canadian Academy of Pathology, Inc.

VOL. 16, NO. 6, P. 584, 2003 Printed in the U.S.A.

Date of acceptance: March 28, 2003.

Presented in part at the 91st annual meeting of the United States and Canadian Academy of Pathology, Chicago, IL, February 2002.

Address reprint requests to: Michael T. Deavers, M.D., Department of Pathology, Box 85, The University of Texas M. D. Anderson Cancer Center, 1515 Holcombe Boulevard, Houston, TX 77030; fax: 713-792-5529; e-mail: mdeavers@mdanderson.org.

DOI: 10.1097/01.MP.0000073133.79591.A1
}

epithelial neoplasms. In addition, WT1, present in normal granulosa cells, is expressed by a majority of SCSTs. Finally, these results demonstrate that calretinin is at least as sensitive as inhibin for ovarian SCSTs overall and that it is more sensitive than inhibin for fibromas and FTs.

KEY WORDS: Calretinin, CD10, EMA, Immunohistochemistry, Inhibin, Keratin, Ovary, Sex cordstromal tumor, WT1.

Mod Pathol 2003;16(6):584-590

Ovarian sex cord-stromal tumors (SCSTs) are relatively infrequent neoplasms that account for approximately $8 \%$ of all primary ovarian tumors (1). They are a heterogeneous group of neoplasms composed of cells derived from gonadal sex cords (granulosa and Sertoli cells), specialized gonadal stroma (theca and Leydig cells), and fibroblasts (2). The morphology of these tumors varies, depending on the cell type or mixture of cell types present, and can range from entirely glandular, as in welldifferentiated Sertoli cell tumors, to entirely spindled, as in cellular fibromas. This varied appearance and the fact that some of these tumors are relatively uncommon can lead to difficulties in diagnosis. Immunohistochemical studies may be useful in those situations when routine microscopic findings fail to indicate a clear diagnosis.

Although various markers have been reported to stain SCSTs, inhibin has proven to be the most helpful to date (3-7). Despite its general utility, however, inhibin is not expressed by all SCSTs (7), and some laboratories do not offer this marker because it is relatively infrequently needed. Thus, having another sensitive marker that is widely available would be advantageous. There have been recent reports that immunostaining for calretinin, which is widely used in mesothelioma panels, may also be useful in the diagnosis of ovarian SCSTs (8-11). Although the majority of the SCSTs in these studies were immunoreactive for calretinin, currently there 
is only one published study examining both calretinin and inhibin expression in the same group of tumors (11). We therefore undertook this study in part to evaluate the utility of calretinin in the diagnosis of SCSTs and to compare it with the inhibin results in the same set of tumors.

WT1, the Wilms' tumor gene product, has been consistently found in both ovarian surface epithelium and in ovarian serous carcinoma (12). Although its mRNA has been detected in granulosa cell tumors and Leydig cell tumors (13), little is known about its immunohistochemical expression in these neoplasms. We therefore also included WT1 in the panel to characterize its expression in ovarian SCSTs.

Because epithelial neoplasms are commonly considered in the differential diagnosis of SCSTs, a cytokeratin cocktail and epithelial membrane antigen (EMA) were added to our panel. As cytokeratin 5/6 (CK5/6), like calretinin, is present in most mesotheliomas (14), it too was included to determine whether it is also expressed by SCSTs or could be used to help distinguish between these tumors. In addition, we tested our set of fibromas with CD10, because ovarian endometrial stromal sarcomas may have areas that resemble fibromas.

\section{MATERIALS AND METHODS}

Paraffin-embedded tissue samples from 53 patients with ovarian SCSTs were obtained from the files of the Department of Pathology at The University of Texas M. D. Anderson Cancer Center. Hematoxylin and eosin stained slides of the tumors were reviewed in all of the cases, and the tumors were categorized as follows using World Health Organization criteria: 17 adult granulosa cell tumors (AGCTs); 4 juvenile granulosa cell tumors (JGCTs); 3 sex cord tumors with annular tubules (SCTATs); 9 Sertoli-Leydig cell tumors (SLCTs), including 1 well differentiated, 4 intermediate, and 4 poorly differentiated; 10 fibromas, 2 of which were cellular; 5 fibrothecomas (FTs); and 5 thecomas. In 8 of the cases (3 AGCT, 1
JGCT, 1 SCTAT, 3 SLCT), the tissue studied was from a metastatic site.

Immunoperoxidase studies were performed on formalin-fixed, paraffin-embedded tissue sections using the avidin-biotin peroxidase complex method in a DAKO autostainer (Carpinteria, CA). The staining was done using the LSAB2 peroxidase kit (DAKO). To enhance the immunostaining, a heatinduced epitope retrieval procedure was performed using a Black \& Decker vegetable steamer (Shelton, CT). Briefly, deparaffinized sections were placed in a container filled with sodium citrate buffer solution ( $\mathrm{pH}$ 6.0), steamed for 45 minutes, and then cooled for 20 minutes before immunostaining. The antigen-antibody immunoreaction was visualized using 3-amino-9-ethylcarbazole as a chromogen. The slides were counterstained with Mayer's hematoxylin. Appropriate positive and negative controls were used.

The primary antibodies included the following: calretinin (1:20; Zymed, South San Francisco, CA), $\alpha$-inhibin (1:50, R1; Oxford Bioinnovate, Oxfordshire, UK), WT1 (1:40; 6FH2, DAKO), cytokeratin cocktail (1:500, AE1/AE3: Chemicon International, Temecula, CA; 1:50, CAM 5.2: Becton Dickinson, San Jose, CA; 1:50, NMF116: DAKO; 1:25, Zym 5.2: Zymed), EMA (1:20, E29; DAKO), and CK5/6 (1:25, D5/16B4; DAKO). Fibromas and FTs were also studied with CD10 (1:70; Novocastra, Newcastle, UK). Nuclear staining with WT1, nuclear and cytoplasmic staining with calretinin, and cytoplasmic staining with the other markers were considered positive. The extent of staining was assessed in a semiquantitative fashion: $0=$ $\leq 5 \%, 1+=6-25 \%, 2+=26-50 \%, 3+=51-75 \%$, and $4+=76-100 \%$.

\section{RESULTS}

Overall immunohistochemical staining results are summarized in Table 1, with details of calretinin, inhibin, WT1, and cytokeratin expression presented in Tables 2-5.

Fifty-two of the 53 tumors (98\%) were positive for calretinin (Figs. 1, 2). In general, the staining was

TABLE 1. Summary of Immunohistochemical Staining Results in Ovarian Sex Cord-Stromal Tumors

\begin{tabular}{|c|c|c|c|c|c|c|c|}
\hline & Calretinin & Inhibin & WT1 & EMA & Cytokeratin & CK5/ 6 & CD10 \\
\hline AGCT & $17 / 17$ (100\%) & $16 / 17$ (94\%) & $11 / 17$ (65\%) & $0 / 17(0 \%)$ & 6/17 (35\%) & $0 / 17(0 \%)$ & - \\
\hline JGCT & $4 / 4(100 \%)$ & $4 / 4(100 \%)$ & $2 / 4(50 \%)$ & $1 / 4(25 \%)$ & $4 / 4(100 \%)$ & $0 / 4(0 \%)$ & - \\
\hline SCTAT & $3 / 3(100 \%)$ & $3 / 3(100 \%)$ & $3 / 3(100 \%)$ & $0 / 3(0 \%)$ & $2 / 3(67 \%)$ & $0 / 3(0 \%)$ & - \\
\hline SLCT & 8/9 (89\%) & $9 / 9(100 \%)$ & $9 / 9(100 \%)$ & $0 / 9(0 \%)$ & $9 / 9(100 \%)$ & $0 / 9(0 \%)$ & - \\
\hline Fibroma & $10 / 10(100 \%)$ & $7 / 10(70 \%)$ & 8/10 (80\%) & $0 / 10(0 \%)$ & $2 / 10(20 \%)$ & $0 / 10(0 \%)$ & $0 / 10(0 \%)$ \\
\hline FT & $5 / 5(100 \%)$ & $1 / 5(20 \%)$ & $5 / 5(100 \%)$ & $0 / 5(0 \%)$ & $0 / 5(0 \%)$ & $0 / 5(0 \%)$ & $0 / 5(0 \%)$ \\
\hline Thecoma & $5 / 5(100 \%)$ & $5 / 5(100 \%)$ & $1 / 5(20 \%)$ & $0 / 5(0 \%)$ & $0 / 5(0 \%)$ & $0 / 5(0 \%)$ & - \\
\hline Overall & $52 / 53(98 \%)$ & $45 / 53(85 \%)$ & $39 / 53(74 \%)$ & $1 / 53(2 \%)$ & $23 / 53(43 \%)$ & 0/53 (0\%) & $0 / 15(0 \%)$ \\
\hline
\end{tabular}

AGCT $=$ adult granulosa cell tumor; JGCT $=$ juvenile granulosa cell tumor; SCTAT $=$ sex cord tumor with annular tubules; SLCT $=$ Sertoli-Leydig cell tumor; FT = fibrothecoma. 
TABLE 2. Calretinin Expression in Ovarian Sex Cord-Stromal Tumors

\begin{tabular}{|c|c|c|c|c|c|}
\hline & $4+$ & $3+$ & $2+$ & $1+$ & 0 \\
\hline AGCT & $6 / 17(35 \%)^{*}$ & $7 / 17(41 \%)^{*}$ & $2 / 17(12 \%)$ & $2 / 17(12 \%)^{*}$ & $0 / 17(0 \%)$ \\
\hline JGCT & $4 / 4(100 \%)^{*}$ & $0 / 4(0 \%)$ & $0 / 4(0 \%)$ & $0 / 4(0 \%)$ & $0 / 4(0 \%)$ \\
\hline SCTAT & $1 / 3(33 \%)$ & $1 / 3(33 \%)$ & $0 / 3(0 \%)$ & $1 / 3(33 \%)^{*}$ & $0 / 3(0 \%)$ \\
\hline SLCT & $5 / 9(56 \%)^{*}$ & $1 / 9(11 \%)$ & $0 / 9(0 \%)$ & $2 / 9(22 \%)^{*}$ & $1 / 9(11 \%)^{*}$ \\
\hline Fibroma & $3 / 10(30 \%)$ & $3 / 10(30 \%)$ & $3 / 10(30 \%)$ & $1 / 10(10 \%)$ & $0 / 10(0 \%)$ \\
\hline FT & $0 / 5(0 \%)$ & $1 / 5(20 \%)$ & $2 / 5(40 \%)$ & $2 / 5(40 \%)$ & $0 / 5(0 \%)$ \\
\hline Thecoma & $5 / 5(100 \%)$ & $0 / 5(0 \%)$ & $0 / 5(0 \%)$ & $0 / 5(0 \%)$ & $0 / 5(0 \%)$ \\
\hline Overall & $24 / 53(45 \%)$ & $13 / 53(25 \%)$ & $7 / 53(13 \%)$ & $8 / 53(15 \%)$ & $1 / 53(2 \%)$ \\
\hline
\end{tabular}

AGCT $=$ adult granulosa cell tumor; JGCT $=$ juvenile granulosa cell tumor; SCTAT $=$ sex cord tumor with annular tubules; SLCT $=$ Sertoli-Leydig cell tumor; FT = fibrothecoma.

$4+-76-100 \%, 3+-51-75 \%, 2+-26-50 \%, 1+-6-25 \%, 0-0-5 \%$.

* Metastatic tumors - 3 AGCT, 1 JGCT, 1 SCTAT, 1 SLCT.

TABLE 3. Inhibin Expression in Ovarian Sex Cord-Stromal Tumors

\begin{tabular}{|c|c|c|c|c|c|}
\hline & $4+$ & $3+$ & $2+$ & $1+$ & 0 \\
\hline AGCT & $3 / 17(18 \%)^{*}$ & 6/17 (35\%) & $5 / 17(29 \%)^{*}$ & $2 / 17(12 \%)$ & $1 / 17(6 \%)^{*}$ \\
\hline JGCT & $3 / 4(75 \%)^{*}$ & $1 / 4(25 \%)$ & $0 / 4(0 \%)$ & $0 / 4(0 \%)$ & $0 / 4(0 \%)$ \\
\hline SCTAT & $2 / 3(67 \%)$ & $1 / 3(33 \%)^{*}$ & $0 / 3(0 \%)$ & $0 / 3(0 \%)$ & $0 / 3(0 \%)$ \\
\hline SLCT & $3 / 9(33 \%)^{*}$ & $1 / 9(11 \%)$ & $2 / 9(22 \%)$ & $3 / 9(33 \%)^{*}, *$ & $0 / 9(0 \%)$ \\
\hline Fibroma & $1 / 10(10 \%)$ & $2 / 10(20 \%)$ & $1 / 10(10 \%)$ & $3 / 10(30 \%)$ & $3 / 10(30 \%)$ \\
\hline FT & $0 / 5(0 \%)$ & $0 / 5(0 \%)$ & $1 / 5(20 \%)$ & $0 / 5(0 \%)$ & $4 / 5(80 \%)$ \\
\hline Thecoma & $5 / 5(100 \%)$ & $0 / 5(0 \%)$ & $0 / 5(0 \%)$ & $0 / 5(0 \%)$ & $0 / 5(0 \%)$ \\
\hline Overall & $17 / 53(32 \%)$ & $11 / 53(21 \%)$ & $9 / 53(17 \%)$ & $8 / 53(15 \%)$ & 8/53 (15\%) \\
\hline
\end{tabular}

AGCT $=$ adult granulosa cell tumor; JGCT $=$ juvenile granulosa cell tumor; SCTAT $=$ sex cord tumor with annular tubules; SLCT $=$ Sertoli-Leydig cell tumor; FT = fibrothecoma.

$4+-76-100 \%, 3+-51-75 \%, 2+-26-50 \%, 1+-6-25 \%, 0-0-5 \%$.

* Metastatic tumors - 3 AGCT, 1 JGCT, 1 SCTAT, 3 SLCT.

TABLE 4. WT1 Expression in Ovarian Sex Cord-Stromal Tumors

\begin{tabular}{|c|c|c|c|c|c|}
\hline & $4+$ & $3+$ & $2+$ & $1+$ & 0 \\
\hline AGCT & $6 / 17(35 \%)^{*}$ & $0 / 17(0 \%)$ & $2 / 17(12 \%)$ & $3 / 17$ (18\%) & $6 / 17(35 \%)^{*}, *$ \\
\hline JGCT & $1 / 4(25 \%)$ & $0 / 4(0 \%)$ & $0 / 4(0 \%)$ & $1 / 4(25 \%)^{*}$ & $2 / 4(50 \%)$ \\
\hline SCTAT & $0 / 3(0 \%)$ & $1 / 3(33 \%)$ & $0 / 3(0 \%)$ & $2 / 3(67 \%)^{*}$ & $0 / 3(0 \%)$ \\
\hline SLCT & $5 / 9(56 \%)^{*}, *$ & $4 / 9(44 \%)^{*}$ & $0 / 9(0 \%)$ & $0 / 9(0 \%)$ & $0 / 9(0 \%)$ \\
\hline Fibroma & $1 / 10(10 \%)$ & $0 / 10(0 \%)$ & $5 / 10(50 \%)$ & $2 / 10(20 \%)$ & $2 / 10(20 \%)$ \\
\hline FT & $2 / 5(40 \%)$ & $2 / 5(40 \%)$ & $0 / 5(0 \%)$ & $1 / 5(20 \%)$ & $0 / 5(0 \%)$ \\
\hline Thecoma & $1 / 5(20 \%)$ & $0 / 5(0 \%)$ & $0 / 5(0 \%)$ & $0 / 5(0 \%)$ & $4 / 5(80 \%)$ \\
\hline Overall & $16 / 53(30 \%)$ & $7 / 53(13 \%)$ & $7 / 53(13 \%)$ & $9 / 53(17 \%)$ & $14 / 53(26 \%)$ \\
\hline
\end{tabular}

AGCT $=$ adult granulosa cell tumor; JGCT $=$ juvenile granulosa cell tumor; SCTAT $=$ sex cord tumor with annular tubules; SLCT $=$ Sertoli-Leydig cell tumor; FT $=$ fibrothecoma.

$4+-76-100 \%, 3+-51-75 \%, 2+-26-50 \%, 1+-6-25 \%, 0-0-5 \%$.

* Metastatic tumors - 3 AGCT, 1 JGCT, 1 SCTAT, 3 SLCT.

strong and diffuse, with $70 \%$ of the cases overall staining for calretinin in the $3+$ to $4+$ range. All of the fibromas and FTs were positive, with $40 \%$ of them staining in the $3+$ to $4+$ range. The only tumor considered to be negative for calretinin was a metastatic SLCT; staining was present in this tumor but was focal $(<5 \%$ of the cells).

Forty-five tumors (85\%) were positive for inhibin (Fig. 3), and staining in $53 \%$ of the cases was $3+$ to $4+$. Of the cases that were negative for inhibin, all but one were fibromas or FTs; $55 \%$ of the fibromas and FTs were negative for inhibin. The other case that was negative was a metastatic AGCT (Fig. 4).

WT1 was present in 39 tumors (74\%). Forty-three percent overall showed staining in the $3+$ to $4+$ range, including all 9 (100\%) of the SLCTs (Fig. 5).
Although WT1 was found in the majority of tumors in most categories, only one of the five thecomas was positive for it.

Twenty-three tumors (43\%) were positive for cytokeratin (Fig. 6). The FT and thecoma categories were the only ones in which all cases were negative. EMA was present in only 1 tumor, a JGCT with 1+ staining (Fig. 7). None of the tumors stained for CK5/6, and none of the fibromas or FTs stained for CD10.

The staining in the three metastatic AGCTs was as follows: inhibin ranged from negative to $4+$; calretinin, from $1+$ to $4+$; and WT1, from negative to $4+$ (Figs. 2, 4). Neither cytokeratin nor EMA was found in these tumors. The tumor that was negative for inhibin showed a $3+$ result for calretinin but was negative for WT1. The meta- 
TABLE 5. Cytokeratin Expression in Ovarian Sex Cord-Stromal Tumors

\begin{tabular}{|c|c|c|c|c|c|}
\hline & $4+$ & $3+$ & $2+$ & $1+$ & 0 \\
\hline AGCT & $1 / 17(6 \%)$ & $1 / 17(6 \%)$ & $2 / 17(12 \%)$ & $2 / 17(12 \%)$ & $11 / 17(65 \%)^{*}, * *$ \\
\hline JGCT & $2 / 4(50 \%)^{*}$ & $0 / 4(0 \%)$ & $0 / 4(0 \%)$ & $2 / 4(50 \%)$ & $0 / 4(0 \%)$ \\
\hline SCTAT & $0 / 3(0 \%)$ & $0 / 3(0 \%)$ & $1 / 3(33 \%)$ & $1 / 3(33 \%)^{*}$ & $1 / 3(33 \%)$ \\
\hline SLCT & $6 / 9(67 \%)^{*}, *, *$ & $1 / 9(11 \%)$ & $2 / 9(22 \%)$ & $0 / 9(0 \%)$ & $0 / 9(0 \%)$ \\
\hline Fibroma & $0 / 10(0 \%)$ & $0 / 10(0 \%)$ & $0 / 10(0 \%)$ & $2 / 10(20 \%)$ & $8 / 10(80 \%)$ \\
\hline FT & $0 / 5(0 \%)$ & $0 / 5(0 \%)$ & $0 / 5(0 \%)$ & $0 / 5(0 \%)$ & $5 / 5(100 \%)$ \\
\hline Thecoma & $0 / 5(0 \%)$ & $0 / 5(0 \%)$ & $0 / 5(0 \%)$ & $0 / 5(0 \%)$ & $5 / 5(100 \%)$ \\
\hline Overall & $9 / 53(17 \%)$ & $2 / 53(4 \%)$ & $5 / 53(9 \%)$ & $7 / 53(13 \%)$ & $30 / 53(57 \%)$ \\
\hline
\end{tabular}

AGCT = adult granulosa cell tumor; JGCT = juvenile granulosa cell tumor; SCTAT = sex cord tumor with annular tubules; SLCT = Sertoli-Leydig cell tumor; FT = fibrothecoma.

$4+-76-100 \%, 3+-51-75 \%, 2+-26-50 \%, 1+-6-25 \%, 0-0-5 \%$.

* Metastatic tumors - 3 AGCT, 1 JGCT, 1 SCTAT, 3 SLCT.

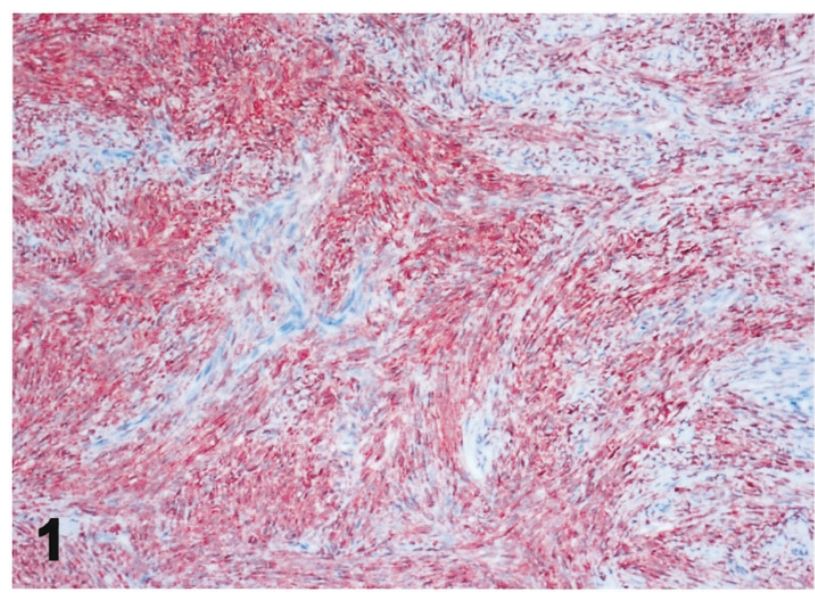

FIGURE 1. Calretinin staining in an ovarian fibroma.

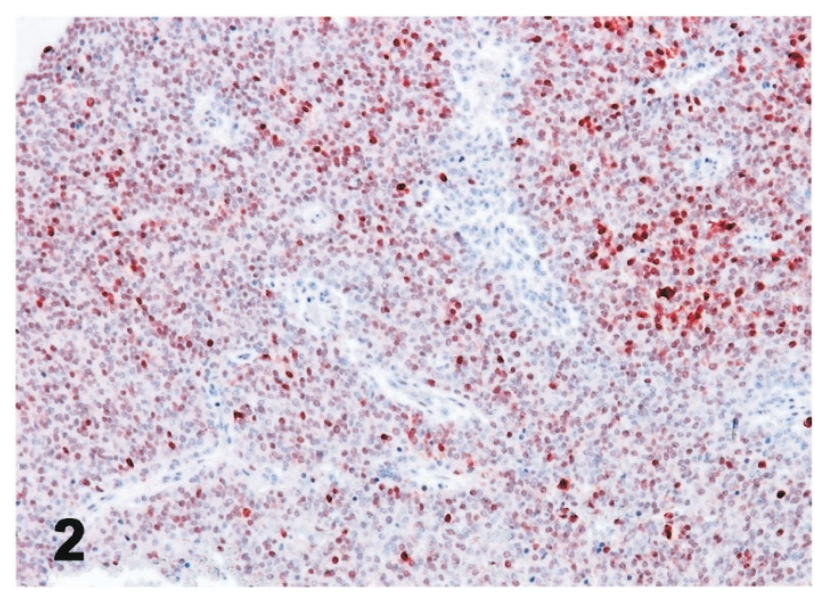

FIGURE 2. Metastatic adult granulosa cell tumor staining for calretinin.

static JGCT was $4+$ for inhibin, calretinin, and cytokeratin and $1+$ for WT1 but was negative for EMA. The metastatic SCTAT was $3+$ for inhibin and $1+$ for calretinin, WT1, and cytokeratin, but was negative for EMA. In the three metastatic SLCTs, the inhibin ranged from $1+$ to $4+$; calretinin, from negative $(<5 \%$ in 1 case $)$ to $4+$; and $\mathrm{WT} 1$, from $3+$ to $4+$; in all three cases, cytokeratin was $4+$, but EMA was negative.

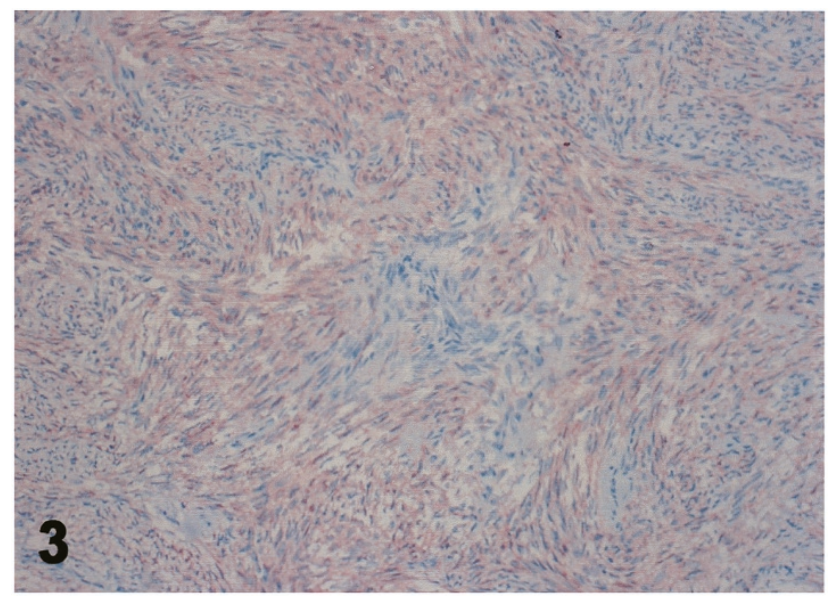

FIGURE 3. Inhibin staining in an ovarian fibroma (same case as Fig. $1)$.

\section{DISCUSSION}

Ovarian SCSTs are a morphologically heterogeneous group of tumors that together make up approximately $8 \%$ of primary ovarian tumors (1). The differential diagnosis for this group can include such diverse entities as carcinoma, sarcoma, germ cell tumor, and melanoma. Because of this and the relative infrequency with which some SCSTs are encountered, immunohistochemistry may be useful in establishing the diagnosis.

Inhibin, especially $\alpha$-inhibin, has generally been found to be the most useful immunomarker to date for SCSTs. Inhibin is a hormonal polypeptide, containing $\alpha$ and $\beta$ subunits, that is present in ovarian granulosa and lutein cells and functions to suppress the production of pituitary gonadotropins (5). Studies performed on paraffin-embedded tissue in recent years have demonstrated that inhibin is a sensitive marker for SCSTs and, in particular, for granulosa cell tumors and SLCTs $(3-7,11)$. However, many of these studies have also found that the staining for inhibin is either weak or entirely absent in fibromas and FTs $(3-7,11)$. Our findings echo the results of these studies in that all of the primary AGCTs, JGCTs, SCTATs, SLCTs, and thecomas in 


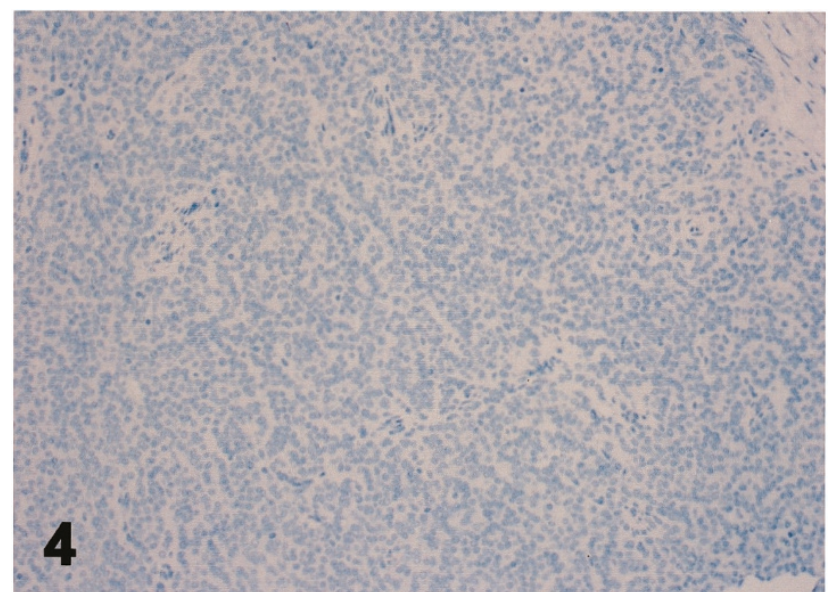

FIGURE 4. Absence of inhibin expression in a metastatic adult granulosa cell tumor (same case as Fig. 2).

the current study were positive for inhibin, while the majority of the fibromas and FTs either showed focal staining or were negative.

Recent studies have suggested that calretinin immunostaining may also be useful for the diagnosis of SCSTs $(8-10,11)$. Calretinin is a $29 \mathrm{KDa}$ calcium binding protein that was originally discovered in neuronal tissue, but was subsequently also found in mesothelial cells and within the ovaries $(8,15,16)$. In two series examining the expression of calretinin in ovarian SCSTs, McCluggage and Maxwell (9) reported that 36 of 37 tumors were positive, while Cao et al. (10) found that 20 of 36 tumors stained. Neither of these studies, however, included inhibin for a direct comparison.

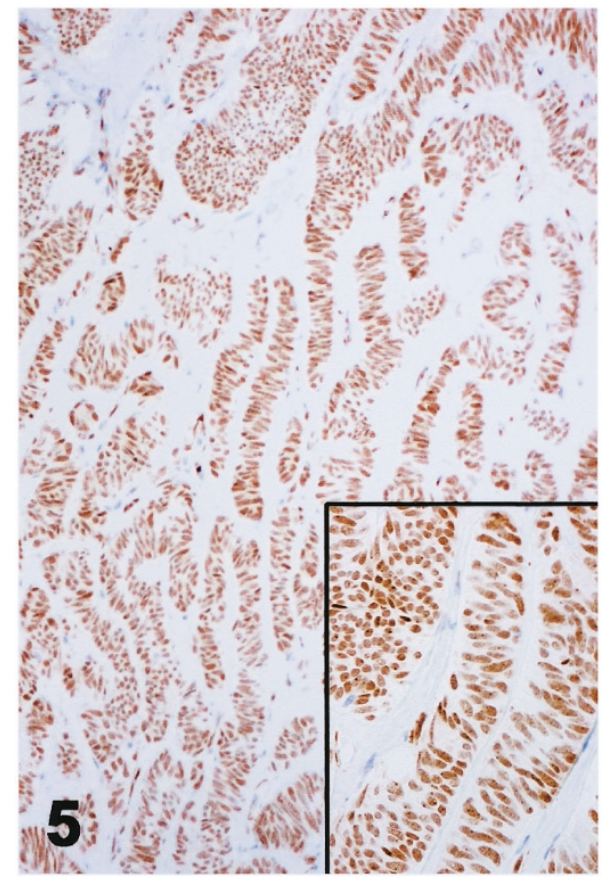

FIGURE 5. Marked expression of WT1 in a Sertoli-Leydig cell tumor.

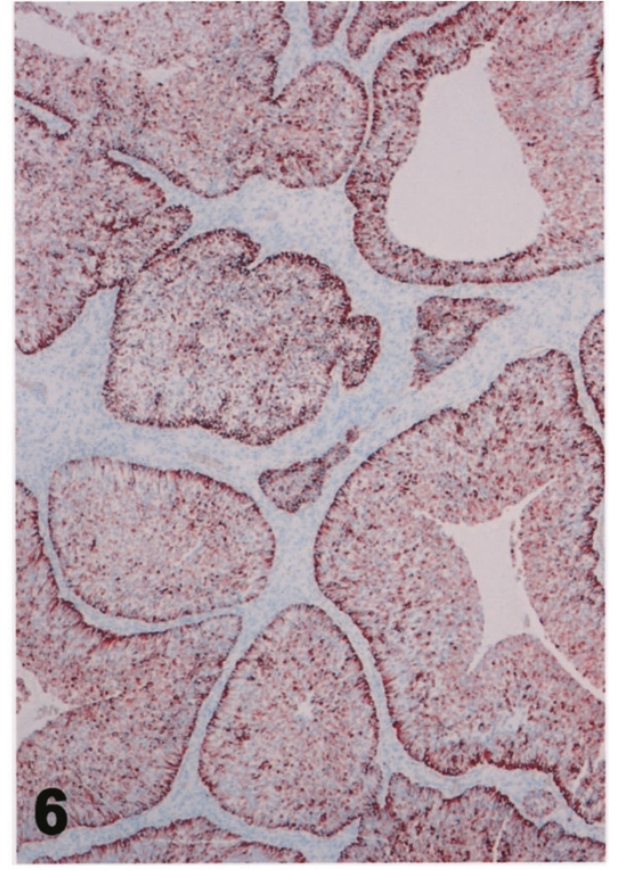

FIGURE 6. Diffuse positivity with keratin cocktail in a juvenile granulosa cell tumor.

In the present study, we also found calretinin to be a sensitive marker for SCSTs. Fifty-two of the 53 tumors (98\%) were positive for calretinin; a metastatic SLCT was the only negative case. This result was somewhat better than that obtained with inhibin, with an $85 \%$ positivity rate. For the AGCTs, JGCTs, SCTATs, SLCTs, and thecomas, the percent-

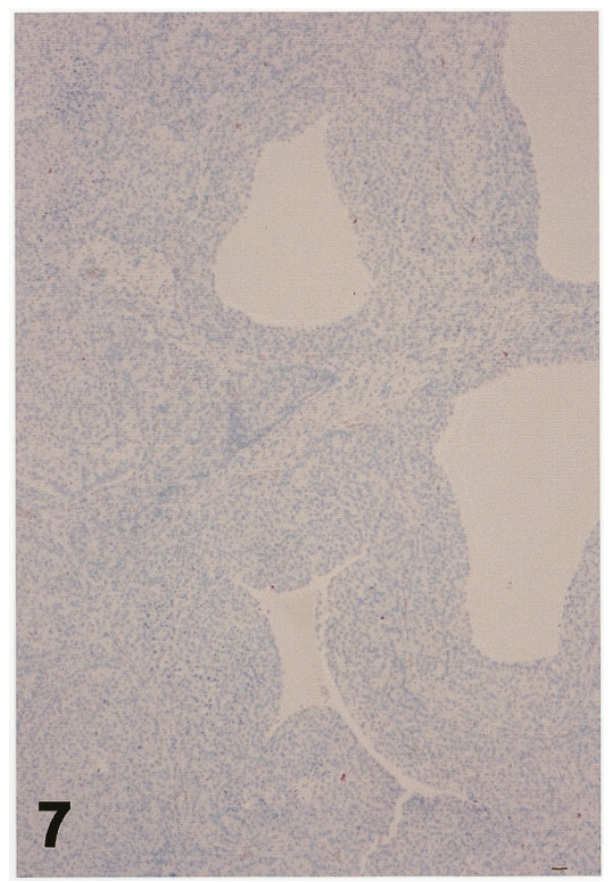

FIGURE 7. Negative EMA in a juvenile granulosa cell tumor (same case as Fig. 6). 
age of tumors expressing calretinin or inhibin and the degree of expression (i.e., 0 to $4+$ ) were comparable. However, calretinin was superior in identifying the fibromas and FTs. Notably, all fibromas were positive for calretinin with $60 \%$ in the $3+$ to $4+$ range, while inhibin was found in only $70 \%$ of these neoplasms, with only $30 \%$ in the $3+$ to $4+$ range. All of the FTs were positive for calretinin, but just 1 of the 5 was positive for inhibin. The findings were similar in one other recent study that examined calretinin and inhibin in the same group of tumors (11). In that study calretinin was found to have an overall sensitivity of $97 \%$ for the diagnosis of sex cord-stromal and fibrous neoplasms, while the sensitivity of inhibin was only $71 \%$. Like the current study, the greatest difference between the two was found to be in the identification of fibromas and FT. Thirty-three of 34 (97\%) fibromas and FT were positive for calretinin, while 14 of the 34 (41\%) were positive for inhibin.

The greater sensitivity of calretinin for fibromas and FTs could be useful in cases in which the differential diagnosis includes endometrial stromal sarcoma with a fibroma-like appearance (17). To further address this issue we studied the fibromas and FTs with CD10, which is known to be expressed in endometrial stromal sarcomas (18). As all 15 of the fibromas/FTs were entirely negative for CD10, the combination of calretinin and CD10 may be useful in helping to distinguish between these SCSTs and endometrial stromal sarcomas with fibroma-like areas.

Interestingly, neither inhibin nor calretinin stained all of the metastatic SCSTs. One of the 3 metastatic AGCTs was negative for inhibin, and staining was only $1+$ in 2 of the 3 metastatic SLCTs. The absence of inhibin expression has been noted before in recurrent AGCT (4). One metastatic SLCT was essentially negative for calretinin and staining was $1+$ for 3 other metastases. However, since calretinin was positive in the inhibin negative metastasis and inhibin staining was present in the calretinin negative tumor, this suggests that the 2 markers could play a complementary role in the diagnosis of metastatic SCSTs.

One caveat about the use of either inhibin or calretinin immunostaining is that both of these markers may occasionally be expressed in tumors that may be included in the differential diagnosis of ovarian SCSTs. For example, inhibin has been reported to be positive in endometrioid adenocarcinoma, clear cell carcinoma, undifferentiated carcinoma, female adnexal tumor of probable Wolffian origin, breast carcinoma, and melanoma $(4,19,20$, 21 ), while calretinin positivity has been described in endometrioid adenocarcinoma, carcinoid tumor, female adnexal tumor of probable Wolffian origin, and breast carcinoma $(8,9,11,21)$. Therefore, in problematic cases, calretinin and inhibin are best used as part of a larger panel of antibodies.

Because one of the most frequent entities to enter into the differential diagnosis of SCSTs is carcinoma, the epithelial markers expressed by these tumors are of interest. Previous studies have shown granulosa cell tumors (33-45\%), SLCTs (82-88\%), and SCTAT to be positive for keratin (22-25). The findings in the present study were similar. Thirtyfive percent of the AGCTs and all of the JGCTs were positive for keratin; two in each category were in the $3+$ to $4+$ range. In addition, all of the SLCTs were reactive, as were 2 of the SCTATs; $78 \%$ of the SLCTs were in the $3+$ to $4+$ range including all 3 of the metastases. Unexpectedly, two fibromas were also positive for keratin, although both were $1+$. In contrast, EMA was not detected in any of the SCSTs, except for $1+$ positivity in a single JGCT. Prior studies have also found SCSTs to be negative for EMA, with the exception of staining in one SLCT $(23,25$, 26). So, although keratin can be found in both carcinomas and SCSTs, EMA may be useful in an immunohistochemical panel to help distinguish between these two entities.

WT1, the Wilms' tumor suppressor gene product, has consistently been found in ovarian surface epithelium and in ovarian serous carcinomas (12). It has also been found in ovarian granulosa cells, where it may play a role in repressing the activity of the $\alpha$ inhibin promoter and thus arrest follicle development $(13,27)$. WT1 mRNA has been found in granulosa cell tumors and SLCTs, but little is known about its immunohistochemical expression in SCSTs. We found WT1 positivity in $74 \%$ of the tumors overall, with variation in expression both between groups and within each category; SLCTs had the greatest degree of expression, as all stained in the $3+$ to $4+$ range. The variation in WT1 expression did not appear to correlate either with the extent of staining for inhibin or calretinin in each tumor or with differentiation in the SLCTs. Interestingly, occasional tumors showing little to no staining for inhibin and calretinin were diffusely positive for WT1. However, because it appears that calretinin and inhibin are generally more sensitive than WT1 for SCSTs, there may be little diagnostic utility for this marker in these tumors.

Although mesothelioma does not generally enter into the differential diagnosis of ovarian SCSTs, because calretinin and WT1 are found in both $(9,14$, 28), we added CK5/6 to our study panel. Although CK5/6 is consistently present in mesothelioma (14), it was not found in any of the SCSTs we tested.

In conclusion, by studying calretinin and inhibin together in the same group of tumors, we found that calretinin compares favorably to inhibin as a marker for ovarian SCSTs. Calretinin is at least as sensitive as inhibin in most categories and is nota- 
bly more sensitive for fibromas and FTs. Together with other markers, such as EMA, it could play an important role in a diagnostic immunohistochemical panel for sex cord-stromal tumors.

\section{REFERENCES}

1. Scully RE, Young RH, Clement PB. Tumors of the ovary, maldeveloped gonads, fallopian tube, and broad ligament. Fascicle 23. 3rd series. Atlas of tumor pathology series. Washington, D.C.: Armed Forces Institute of Pathology; 1998.

2. Scully RE. Histological typing of ovarian tumors. 2nd ed. World Health Organization international histological classification of tumours series. Berlin: Springer; 1999.

3. Costa MJ, Ames PF, Walls J, Roth LM. Inhibin immunohistochemistry applied to ovarian neoplasms: a novel, effective, diagnostic tool. Hum Pathol 1997;28:1247-54.

4. Hildebrandt RH, Rouse RV, Longacre TA. Value of inhibin in the identification of granulosa cell tumors of the ovary. Hum Pathol 1997;28:1387-95.

5. Rishi M, Howard LH, Bratthauer GL, Tavassoli FA. Use of monoclonal antibody against human inhibin as a marker for sex cord-stromal tumor of the ovary. Am J Surg Pathol 1997; 21:583-9.

6. Stewart CJ, Jeffers MD, Kennedy A. Diagnostic value of inhibin immunoreactivity in ovarian gonadal stromal tumours and their histologic mimics. Histopathology 1997;31:67-74.

7. Kommoss F, Oliva E, Bhan AK, Young RH, Scully RE. Inhibin expression in ovarian tumors and tumor-like lesions: an immunohistochemical study. Mod Pathol 1998;11:656-64.

8. Doglioni C, Dei Tos AP, Laurino L, Iuzzolino P, Chiarelli C, Celio MR. Calretinin: a novel immunocytochemical marker for mesothelioma. Am J Surg Pathol 1996;20:1037-46.

9. McCluggage WG, Maxwell P. Immunohistochemical staining for calretinin is useful in the diagnosis of ovarian sex cordstromal tumours. Histopathology 2001;38:403-8.

10. Cao QJ, Jones JG, Li M. Expression of calretinin in human ovary, testis, and ovarian sex cord-stromal tumors. Int J Gynecol Pathol 2001;20:346-52.

11. Movahedi-Lankarani S, Kurman RJ. Calretinin, a more sensitive but less specific marker than $\alpha$-inhibin for ovarian sex cord-stromal neoplasms: an immunohistochemical study of 215 cases. Am J Surg Pathol 2002;26:1477-83.

12. Shimizu M, Toki T, Takagi Y, Konishi I, Fujii S. Immunohistochemical detection of the Wilms' tumor gene (WT1) in epithelial ovarian tumors. Int J Gynecol Pathol 2000;19:15863.

13. Coppes MJ, Ye Y, Rackley R, Zhao XL, Liefers GJ, Casey G, et al. Analysis of WT1 in granulosa cell and other sex cordstromal tumors. Cancer Res 1993;53:2712-4.

14. Ordonez NG. Role of immunohistochemistry in distinguishing epithelial peritoneal mesotheliomas from peritoneal and ovarian serous carcinomas. Am J Surg Pathol 1998;22:120314.

15. Pohl V, Van Rampelbergh J, Mellaert S, Parmentier M, Pochet R. Calretinin in rat ovary: an in situ hybridization and immunohistochemical study. Biochem Biophys Acta 1992; 1160:87-94.

16. Bertschy S, Genton CY, Gotzos V. Selective immunocytochemical localization of calretinin in the human ovary. Histochem Cell Biol 1998;109:59-66.

17. Young RH, Prat J, Scully RE. Endometrioid stromal sarcomas of the ovary: a clinicopathologic analysis of 23 cases. Cancer 1984;53:1143-55.

18. Toki T, Shimizu M, Takagi Y, Ashida T, Konishi I. CD10 is a marker for normal and neoplastic endometrial stromal cells. Int J Gynecol Pathol 2002;21:41-7.

19. McCluggage WG, Maxwell P. Adenocarcinomas of various sites may exhibit immunoreactivity with anti-inhibin antibodies. Histopathology 1999;35:216-20.

20. Pelkey TJ, Frierson HF Jr, Mills SE, Stoler MH. The diagnostic utility of inhibin staining in ovarian neoplasms. Int J Gynecol Pathol 1998;17:97-105.

21. Devouassoux-Shisheboran M, Silver SA, Tavassoli FA. Wolffian adnexal tumor, so-called female adnexal tumor of probable Wolffian origin (FATWO): immunohistochemical evidence in support of a Wolffian origin. Hum Pathol 1999;30: 856-63.

22. Benjamin E, Law S, Bobrow LG. Intermediate filaments cytokeratin and vimentin in ovarian sex cord-stromal tumours with correlative studies in adult and fetal ovaries. J Pathol 1987;152:253-63.

23. Costa MJ, De Rose PB, Roth LM, Brescia RJ, Zaloudek CJ, Cohen C. Immunohistochemical phenotype of ovarian granulosa cell tumors: absence of epithelial membrane antigen has diagnostic value. Hum Pathol 1994;25:60-6.

24. Gordon MD, Corless C, Renshaw AA, Beckstead J. CD99, keratin, and vimentin staining of sex cord-stromal tumors, normal ovary, and testis. Mod Pathol 1998;11:769-73.

25. Riopel MA, Perlman EJ, Seidman JD, Kurman RJ, Sherman ME. Inhibin and epithelial membrane antigen immunohistochemistry assist in the diagnosis of sex cord stromal tumors and provide clues to the histogenesis of hypercalcemic small cell carcinomas. Int J Gynecol Pathol 1998;17:46-53.

26. Guerrieri C, Franlund B, Malmstrom H, Boeryd B. Ovarian endometrioid carcinomas simulating sex cord-stromal tumors: a study using inhibin and cytokeratin 7. Int J Gynecol Pathol 1998;17:266-71.

27. Hsu SY, Kubo M, Chun S-Y, Haluska FG, Housman DE, Hsueh AJW. Wilms' tumor protein WT1 as an ovarian transcription factor: decreases in expression during follicle development and repression of inhibin-alpha gene promoter. Mol Endocrinol 1995;9:1356-66.

28. Amin KM, Litzky LA, Symthe WR, Mooney AM, Morris JM, Mews DJ, et al. Wilms' tumor 1 susceptibility (WT1) gene products are selectively expressed in malignant mesothelioma. Am J Pathol 1995;146:344-56. 